\title{
PENCEGAHAN TERJADINYA RESIKO DE QUERVAIN SYNDROM PADA PENGGUNA GADGET
}

\author{
Nova Relida Samosir1), Ayu Permata ${ }^{1)}$, Siti Muawanah' \\ 1)Program Studi D-III Fisioterapi, Fakultas Kedokteran dan Ilmu Kesehatan, \\ Universitas Abdurrab \\ email: nova.relida@univrab.ac.id
}

\begin{abstract}
ABSTRAK
Penggunaan perangkat Teknologi Informasi dan Komunikasi (TIK) sudah sangat luas, hampir semua kegiatan manusia tidak lepas dari perangkat teknologi, salah satu contohnya adalah penggunaan gadget diantaranya seperti telepon genggam, telepon pintar dan tablet. Tidak banyak yang menyadari bahwa pemakaian gadget dapat menimbulkan beberapa resiko. Resiko yang dapat timbul yaitu penyakit De Quervain Syndrome. De Quervain Syndrome adalah suatu bentuk peradangan dari selaput tendon yang di sertai rasa nyeri pada pangkal ibu jari meluas sampai ke lengan bagian bawah, adanya pembengkakan tendon serta menyebabkan dan melibatkan ruang gerak tendon menjadi sempit (dikenal dengan istilah tenosinovitis) yang berada di sarung synovial, yaitu yang menyelubungi otot abductor pollicis longus dan extensor pollicis brevis. Tujuan pengabdian masyarakat ini adalah untuk mengetahui dampak pengetahuan akan pencegahan terjadinya resiko de quervain syndrome pada pengguna gadget di SMK Muhammadiyah 2 Pekanbaru-Riau. Pengabdian masyarakat ini berupa ceramah dan diskusi, pemeriksaan serta pengukuran deteksi dini pada skala nyeri dengan skala VAS (Verbal Analog Scale). Teknik analisis data deskriptif.Kegiatan pengabdian masyarakat dihadiri guru dan siswa sejumlah 54 orang dengan rentang usia 15 sampai dengan 17 tahun. Pada siswa sejumlah 54, nilai rata rata pre tes dan post tes maka ada peningkatan pengetahuan sebesar $40 \%$. Ada dampak peningkatan pengetahuan pada siswa akan manfaat pencegahan terjadinya resiko de quervain syndrome pada pengguna gadget di SMK Muhammadiyah 2 Pekanbaru-Riau.
\end{abstract}

Kata Kunci: De Quervain syndrom, Verbal Analog Scale, Gadget

\section{ABSTRACT}

The use of Information and Communication Technology (ICT) devices is very broad, almost all human activities cannot be separated from technological devices, one example of which is the use of gadgets such as mobile phones, smartphones and tablets. Not many realize that using a gadget can pose a number of risks. Risks that can arise are De Quervain Syndrome. De Quervain Syndrome is a form of inflammation of the tendon membrane which is accompanied by pain at the base of the thumb extending to the lower arm, the presence of tendon swelling and causing and involving the narrow tendon movement (known as tenosynovitis) which is in synovial sheaths, that is covering the abductor pollicis longus and extensor pollicis brevis muscles. The purpose of this community service is to find out the impact of knowledge on the prevention of the risk of de quervain syndrome in gadget users at Muhammadiyah 2 Vocational School Pekanbaru-Riau. This community service is in the form of lectures and discussions, examinations and measurements of early detection on the scale of pain with a VAS (Verbal Analog Scale) scale. Descriptive data analysis technique. Of community service activities were attended by students with a total of 54 people ranging in age from 15 to 17 years. In the number of students 54, the average value of pre-test and post-test, there is an increase in knowledge by $40 \%$. is an impact of increasing knowledge in students about the benefits of preventing the risk of de quervain syndrome in gadget users at Muhammadiyah 2 Vocational School PekanbaruRiau.

Key words: De Quervain Syndrom, Verbal Analog Scale, Gadget 


\section{PENDAHULUAN}

Penggunaan perangkat Teknologi Informasi dan Komunikasi (TIK) sudah sangat luas, hampir semua kegiatan manusia tidak lepas dari perangkat teknologi.Seolah-olah hidup manusia sudah sangat tergantung pada kemampuan perangkat tersebut yang memang diciptakan untuk membantu aktivitas manusia.Perangkat teknologi tidak hanya digunakan oleh kalangan menengah atas saja, tetapi saat ini kalangan menengah ke bawahpun sudah banyak yang menggunakan teknologi, salah satu cntohnya adalah penggunaan gadget diantaranya seperti handphone, computer, dan televisi.Walaupun sudah banyak manfaat yang dapat diperoleh dari pemakaian perangkat teknologi informasi dan komunikasi, Namun belum banyak yang menyadari bahwa pemakaian perangkat tersebut dapat juga menimbulkan risiko tersendiri. Risiko yang dimaksud adalah penyakit akibat kerja yang disebabkan oleh pemakaian perangkat TIK, terutama pemakaiannya dalam waktu yang lama secara terus menerus, Salah satunya yaitu kondisi De Quervain Syndrome.

De Quervain Syndrome adalah suatu bentuk peradangan dari selaput tendon yang di sertai rasa nyeri pada pangkal ibu jari meluas sampai ke lengan bagian bawah, adanya pembengkakan tendon serta menyebabkan dan melibatkan ruang gerak tendon menjadi sempit (dikenal dengan istilah tenosinovitis) yang berada di sarung synovial, yaitu yang menyelubungi otot abductor pollicis longus dan extensor pollicis brevis [1].

Dalam penelitian yang sudah ada, rata-rata sekitar $0,5 \%$ pria dan $1,3 \%$ wanita usia kerja menderita De Quervain tenosynovitis, sehingga dalam dua juta hari kerja yang hilang per tahun di Jerman. Statistik menunjukkan bahwa tingkat prevalensi De Quervain Syndrome dalam populasi normal adalah 3,7\%. Tingkat prevalensi pada wanita adalah 3-4 kali lebih banyak dari pada pria [2].

Salah satu penanganan untuk kondisi De Quervain Syndrome ini yakni melalui fisioterapi, Peran fisioterapi pada kondisi De Quervain Syndrome sangat ditentukan oleh kondisi yang problemnya diidentifikasi berdasarkan hasil fisioterapi yang meliputi assessment, diagnosis, planning, intervention dan evaluasi. Intervensi fisioterapi berupa aspek pronative,preventive, curative, rehabilitative dan maintenance dengan modalitasdasar fisioterapi [3].

Adapun Intervesi fisioterapi yang dapat diberikan untuk mengurangi nyeri pada kondisi De Quervain Syndrome pada kesempatan pengabdian kepada masyarakat kali ini yaitu dengan pemberian terapi latihan. Terapi latihan adalah salah satu modalitas fisioterapi dengan menggunakan gerak tubuh baik secara aktif maupun pasif untuk pemeliharaan dan perbaikan kekuatan, ketahanan dan kemampuan kardiovaskuler, mobilitas dan fleksibilitas, stabilitas, rileksasi, koordinasi, keseimbangan dan kemampuan fungsional.

\section{TINJAUAN PUSTAKA}

De Quervain Syndromemerrupakan bentuk peradangan dari selaput tendon yang di sertai rasa nyeri pada pangkal ibu jari meluas sampai ke lengan bagian bawah, adanya pembengkakan tendon serta menyebabkan dan melibatkan ruang gerak tendon menjadi sempit (dikenal dengan istilah tenosynovitis) yang berada di sarung synovial, yaitu yang menyelubungi otot abductor pollicis longus dan extensor pollicis brevis.

De Quervain syndrome merupakan peradangan dengan gejala rasa sakit pada tendon ibu jari sampai ke pergelangan tangan (dikenal dengan istilah tenosinovitis). Adanya pembengkakan tendon serta selubung tendon akan menyebabkan ruang gerak dari tendon menjadi sempit dan dapat menimbukan adanya gesekan yang dapat 
menimbulkan nyeri pada pangkal ibu jari dan meluas sampai ke lengan bagian bawah[4].

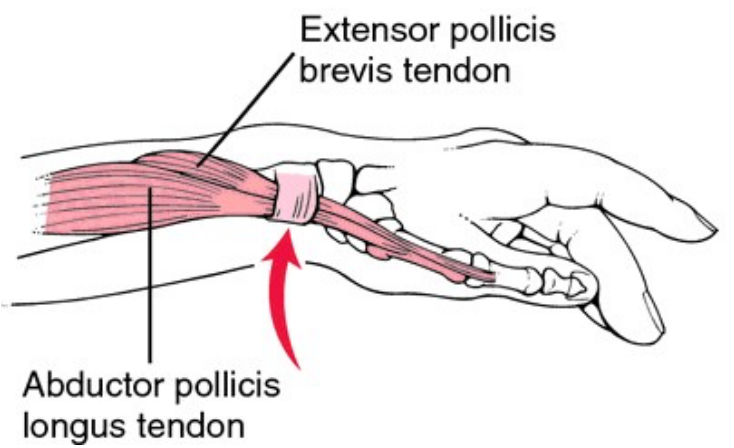

Gambar 1: De Quervain Syndrome Sumber: Wheeless, 2007

De Quervain syndrome merupakan nyeri akibat pemakaian tangan dalam melakukan pekerjaan yang berulang-ulang sehingga terjadi pembengkakan serta iritasi pada procesus styloideus lateralis dan terjadi inflamasi. De Quervain terjadi karena adanya peradangan atau Tendosynovitis dan adanya proses degenerasi myoxid yang konsisten dengan proses degenerative yang kronik. Tendon yang mengalami peradangan adalah tendon otot extensor pollicis brevis dan tendon otot abductor pollicis longus yang merupakan dua otot yang bekerja saling berdampingan yang fungsinya hampir sama yaitu menggerakkan ibu jari menjauh dari tangan [5].

Pemeriksaan spesifik atau khusus dilakukan untuk mendeteksi antara tendon Abductor Pollicis Longus (APL) dan Ekstensor Pollicis Brevis (EPB), yaitu dengan prosedur tes dengan posisi awal lengan bawah mid-posisi sementara jemari tangan lainya menggenggam ibu jari dalam posisi tangan dikepal dan tersanggah secara comfortable di atas bad atau pillow dan selanjutnya menggerakkan tangan pasien secara pasif kea rah ulnar deviasi. Positif tes limitasi gerak dan nyeri pada atas aspek radial wrist joint.

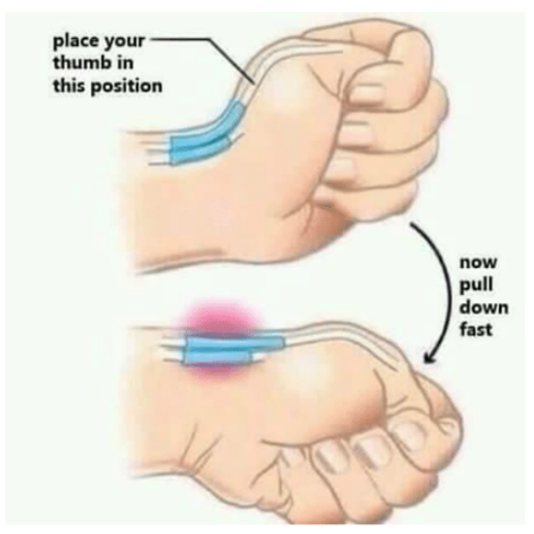

Gambar 2. Finklestain's Test

Sumber: Mujianto, 2013 
Visual analogue Scale (VAS)merupakan alat ukur lainnya yang digunakan untuk memeriksa intensitas nyeri dan secara khusus meliputi $0-10 \mathrm{~cm}$ garis, dengan setiap ujungnya ditandai dengan level intensitas nyeri (ujung kiri diberi tanda " no pain" dan ujung kanan diberi tanda "bad pain" (nyeri hebat). Pasien diminta untuk menandai disepanjang garis tersebut sesuai dengan level intesitas nyeri yang dirasakan pasien, kemudian jaraknya diukur dari batas kiri sampai pada tanda yang diberikan pasien dan itulah skornya yang menujukkan level intensitas nyeri.

Terapi latihan adalah salah satu modalitas fisioterapi dengan menggunakan gerak tubuh baik secara aktif maupun pasif untuk pemeliharaan dan perbaikan kekuatan, ketahanan dan kemampuan kardiovaskuler, mobilitas dan fleksibilitas, stabilitas, rileksasi, koordinasi, keseimbangan dan kemampuan fungsional. Dari keseluruhan proses fisioterapi, terapi latihan (exercise therapy) sering merupakan kegiatan utama yang didukung oleh modalitas-modalitas lain. Hal ini dikarenakan pengembalian fungsi gerak sering merupakan tujuan utama dari proses fisioterapi [6].

Terapi latihan dilakukan pada fase kronis untuk merahibilitasi penderita cedera atau gangguan penyakit agar dapat mengembalikan fungsi tubuh seperti atau mendekati fungsi semula. Secara keseluruhan, terapi latihan (exercise therapy) merupakan aktivitas fisik yang sistematis dan bertujuan untuk :

1. Memperbaiki atau mencegah gangguan fungsi tubuh

2. Memperbaiki kecacatan

3. Mencegah atau mengurangi faktor resiko gangguan kesehatan

4. Mengoptimalkan status kesehatan dan kebugaran.

Terapi latihan dirancang untuk menyesuaikan kebutuhan individual setiap penderita dengan tujuan utama mengoptimalkan fungsi tubuh. Fungsi tubuh dalam hal ini berkaitan dengan beberapa parameter seperti keseimbangan, kebugaran kardiorespirasi, koordinasi, fleksibilitas, mobilitas, kontrol motorik, kontrol neuromuskular, kontrol postural dan stabilitas.

1. Keseimbangan merupakan kemampuan untuk mempertahankan tubuh melawan gaya gravitasi dengan mempertahankan pusat massa tubuh dengan penyokong yang ada tanpa terjatuh dengan mekanisme sistem motorik dan sensorik.

2. Kebugaran kardiorespirasi merupakan kemampuan untuk melaksanakan aktivitas intensitas sedang misalkan: berjalan, berenang, jogging atau bersepeda) secara repetitif dalam jangka waktu yang relatif lama. Kebugaran kardiorespirasi sering disebut sebagai ketahanan kardiopulmoner.

3. Koordinasi merupakan usaha tubuh untuk menyeimbangkan gerakan dengan jalan melakukan gerakan otot dalam waktu, intensitas dan urutan yang tepat, sehingga dapat menampilkan gerakan yang efektif dan akurat baik secara sadar maupun tidak sadar. Fleksibilitas merupakan kemampuan untuk bergerak bebas tanpa hambatan dengan jangkauan gerak yang baik. 
4. Mobilitas merupakan kemampuan suatu struktur atau segmen tubuh untuk bergerak atau digerakkan. Mobilitas pasif bergantung pada kontraktilitas jaringan lunak sedangkan mobilitas aktif memerlukan kerja neuromuscular.

5. Kerja otot merupakan kapasitas otot untuk memproduksi tegangan dan melaksanakan aktivitas fisik. Kerja otot meliputi kekuatan, tenaga dan ketahanan otot.

6. Kontrol neuromuscular merupakan interaksi sistem sensorik dan motorik yang dapat mencetuskan kerja sinergis, agonis, antagonis untuk merespon informasi propioseptor dan kinestetik yang kemudian pada gilirannya memproduksi gerakan dan urutan yang tepat dan terkoordinasi.

7. Kontrol postural merupakan usaha tubuh untuk mempertahankan stabilitas postur tubuh.

8. Stabilitas merupakan kemampuan sistem neuromuscular melalui kerja otot sinergis untuk mempertahankan segmen tubuh dalam posisi stabil pada keadaan bergerak maupun diam.

Keseluruhan sistem tersebut bereaksi, beradaptasi dan berkembang sebagai respon terhadap beban fisik (physical stress) termasuk aktivitas fisik. Aktivitas fisik membantu tubuh untuk memelihara kemampuan fungsional tubuh, ketahanan kardiorespirasi dan kemampuan mobilitas. Sebagai contoh ketiadaan aktivitas fisik dalam jangka waktu lama dapat menimbulkan kelemahan otot dan tulang. Absennya aktivitas fisik juga dapat mengurangi ketahanan kardiprespirasi.

Walaupun demikian apabila dilakukan secara berlebihan, aktivitas fisik dapat pula mengakibatkan cedera dalam bentuk antara lain strain, sprain, fraktur maupun kondisi kronis degeneratif. Sehingga terapi latihan harus dirancang agar aktivitas fisik yang diprogramkan sesuai dengan kebutuhan penderita dengan resiko cedera akibat latihan seminimal mungkin dan mendapatkan peningkatan kapasitas fungsional tubuh semaksimal mungkin.

\section{METODE PELAKSANAAN}

Kegiatan pengabdian dilaksanankan pada tanggal 09 bulan November 2018 di SMK Muhammadiyah 2 Pekanbaru. Metode yang dilakukan dalam pengabdian ini adalah dengan metode ceramah, stimulasi dengan melakukan beberapa pemeriksaan terkait untuk mendeteksi nyeri disebabkan de quervain syndrom, demonstrasi, diskusi dan Tanya jawab. Bahan dan alat yang diperlukan dalam pengabdian ini adalah leptop, infokus, white board, leaflet, banner, untuk menunjang kegiatan penyuluhan.

\section{HASIL DAN PEMBAHASAN}

Kegiatan pengabdian masyarakat dihadiri siswa sejumlah 54 orang dengan rentang usia 15 sampai dengan 17 tahun. Pada siswa sejumlah 54, nilai rata rata pre tes dan post tes maka ada peningkatan pengetahuan sebesar $40 \%$. 


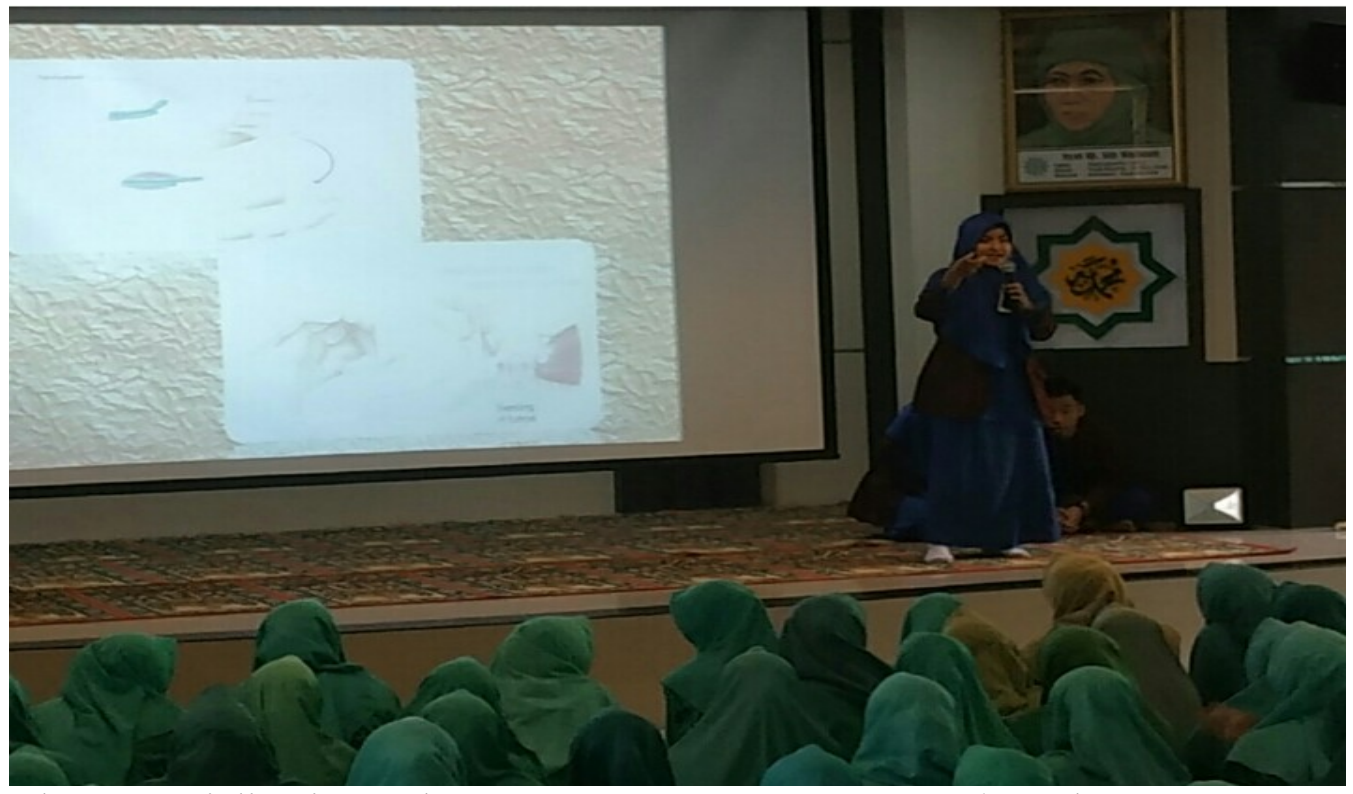

Gambar 3. Sosialisasi pemahaman tentang De Quervain Syndrom dan penanganannya

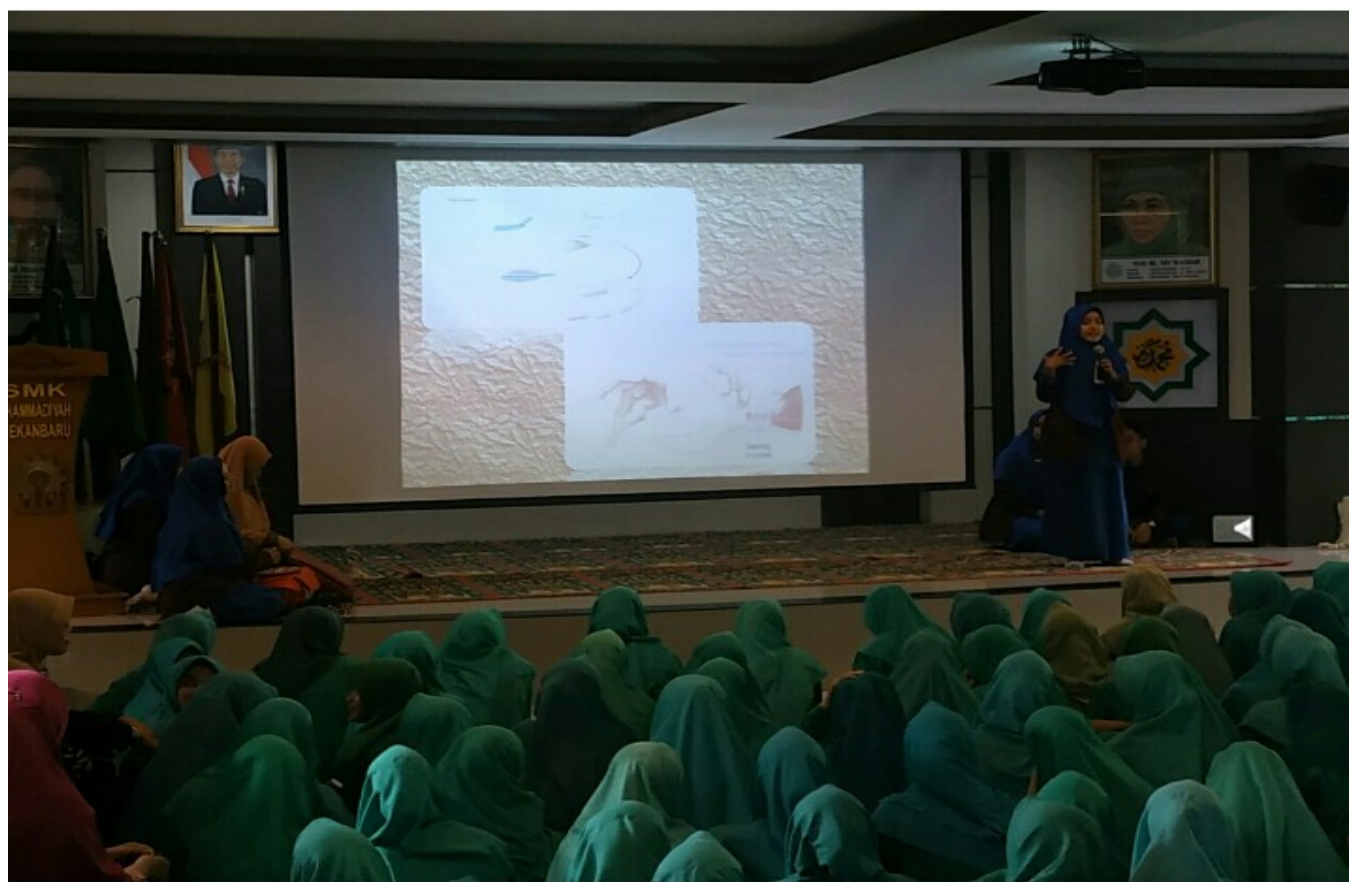

Gambar 4. Sosialisasi pemahaman tentang De Quervain Syndrom dan penanganannya 


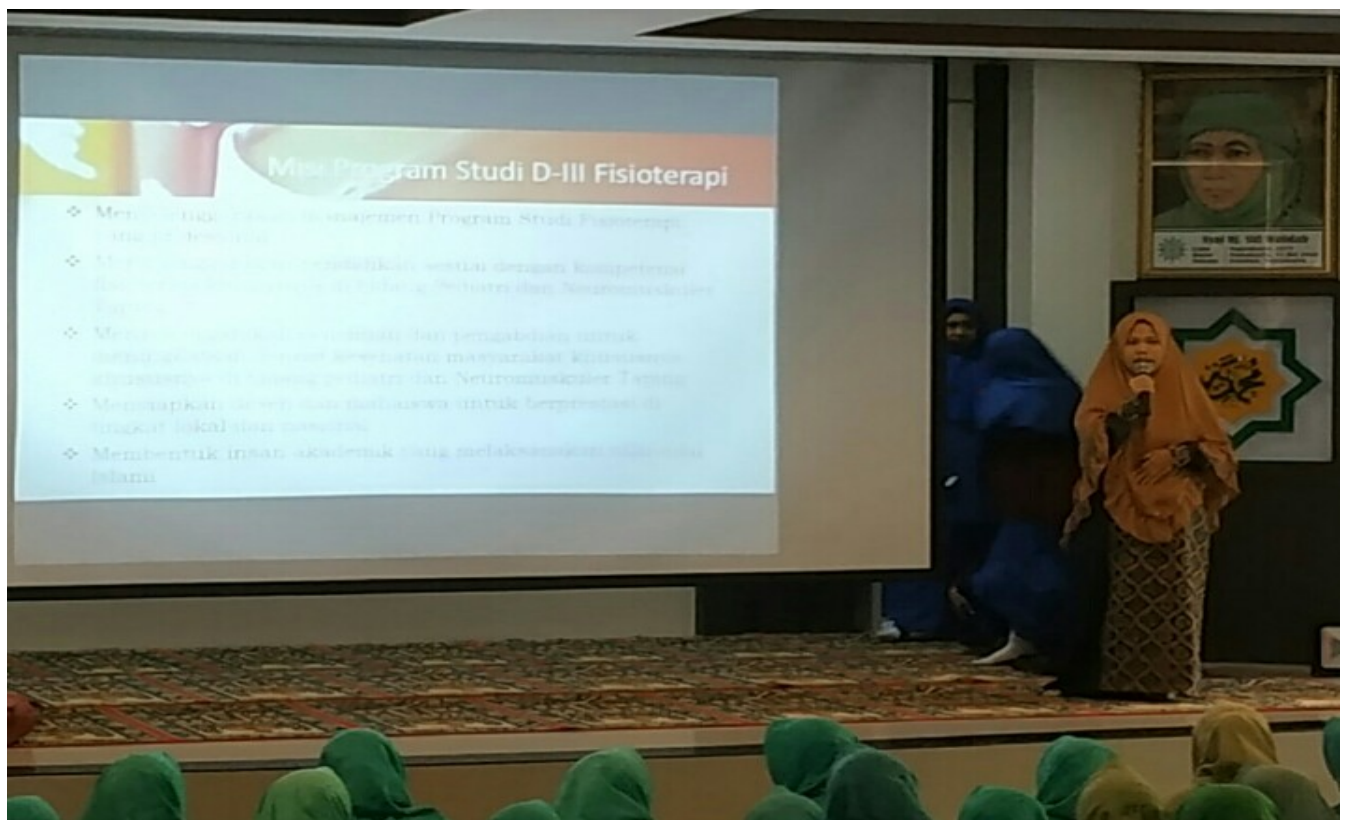

Gambar 5. Sosialisasi pemahaman tentang De Quervain Syndrom dan penanganannya

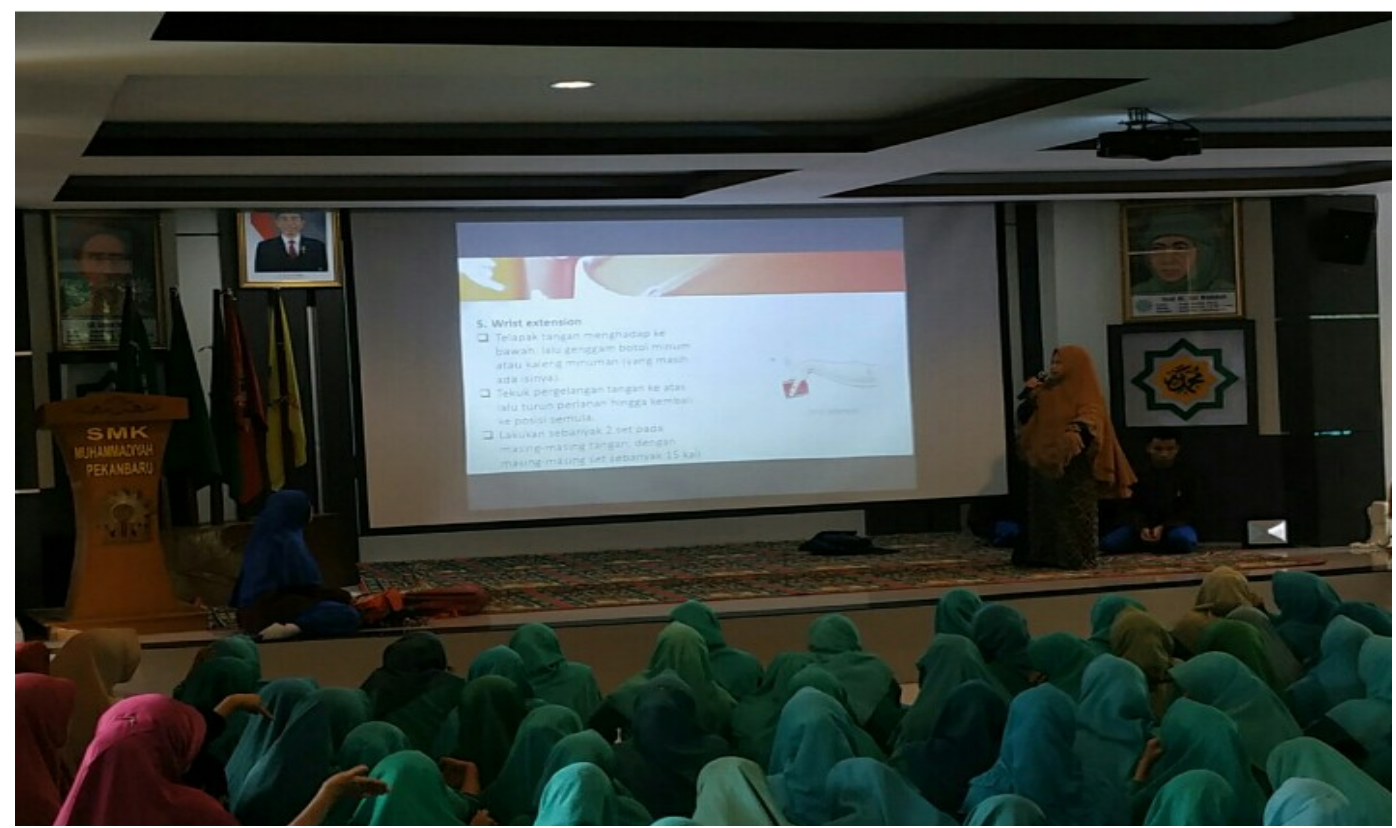

Gambar 6. Sosialisasi pemahaman tentang De Quervain Syndrom dan penanganannya

\section{KESIMPULAN}

Pengabdian yang dilaksanakan di SMK Muhammadiyah 2 Pekanbaru dapat terselenggara dengan baik, hal ini tak luput dari bantuan beberapa pihak. Adapun hal yang dapat disimpulkan pada pelaksanaan kegiatan pengabdian ini adalah :

a. Meningkatnya pemahaman siswa terhadap penyebab de quervain sindrom.

b. Meningkatnya pemahaman siswa terhadap manfaat Terapi Latihan untuk mencegah de quervain syndrome

c. Meningkatnya pemahaman siswa terhadap pencegahan de quervain syndrome 


\section{DAFTAR PUSTAKA}

[1] Ilyas A, Ast M, Schaffer AA, Thoder J.2007."De quervain tenosynovitis of the wrist". J Am Acad Orthop Surg 15 (12): 757-64.

[2] Lane LB, Boretz RS, Stuchin SA. 2001. Treatment of de Quervain's disease role of conservative management. J Hand Surg [Br] Jun;26(3):258-60.

[3] Wright, PE. 2004. Carpal Tunnel, Ulnar Tunnel, and Stenosing Tenosynovitis in Campbell-Operative Orthopaedics, 10th EditionPart XVIII, chapter 73.

[4] Read HS, Hooper G, Davie R. 2000. "Histological appearances in post-partum de Quervain's disease". J Hand Surg [Br] 25 (1): 70-2.

[5] Slviya A and Wilson N. 2006.Patofisiologi Konsep Klinis Proses-Proses Penyakit Edisi 6.EGC.

[6] Kisner, Carolyn. 2012. Theraupeutic Exercise Foundation and Techique. F.A Davis Company. Philadepia. 